\title{
OiSaeng Hong \\ Hearing loss among operating engineers in American construction industry
}

Received: 21 July 2004 / Accepted: 2 March 2005 / Published online: 14 July 2005

(C) Springer-Verlag 2005

\begin{abstract}
Objective: Occupational noise exposure and noise-induced hearing loss (NIHL) among construction workers has long been recognized as a problem in the United States, yet little is known about the prevalence of NIHL among American construction workers. The purpose of this study was to determine the prevalence and characteristics of hearing loss among operating engineers (OEs) who operate heavy construction machinery. Method: As a part of hearing protection intervention, an audiometric test was conducted for both ears at frequencies 0.5 through $8 \mathrm{kHz}$ in the soundproof booth. Prior to the audiometric test, a paper-pencil prehearing test questionnaire was administered and an otoscopic examination was completed. Prevalence of hearing loss was determined based on hearing threshold levels (HTLs) in the worst ear with a low fence of $25 \mathrm{~dB}$. Result: A total of 623 workers were included in the analysis and they were predominantly middle-aged Caucasian males (mean age $=43$ years, Caucasian $=$ $90 \%$, male $=92 \%$ ). Over $60 \%$ of OEs showed hearing loss in the noise-sensitive higher frequencies of 4 and $6 \mathrm{kHz}$. The rate of hearing loss was particularly higher among workers who reported longer years of working in the construction industry. Workers showed significantly poorer hearing in the left ear, and a typical characteristic of NIHL, a V-notch at 4 or $6 \mathrm{kHz}$, was not shown in this population. Thirty-eight percent reported ringing/buzzing in the ear and $62 \%$ indicated having problems in understanding what people say in loud noise. Average reported use of hearing protection devices (HPDs) was $48 \%$ of the time they were required to be used. Significant inverse relationship was found between higher frequency $(4-6 \mathrm{kHz})$ hearing loss and use of HPDs $(r=-0.134, p<0.001)$. Workers using HPDs more had
\end{abstract}

O. Hong

Health Promotion \& Risk Reduction Program,

School of Nursing, University of Michigan, 400 N. Ingalls,

Room 3182, Ann Arbor, MI 48109-0482, USA

E-mail: oshong@umich.edu

Tel.: + 1-734-763-3450

Fax: + 1-734-647-0351 significantly better hearing than those who did not. Conclusion: The study demonstrated a significant NIHL problem and low use of HPDs in OEs. An effective hearing conservation program, including a periodic audiometric testing and hearing protection intervention, for this study population should be in place.

Keywords Noise $\cdot$ Hearing loss $\cdot$ Construction workers $\cdot$ Hearing protection $\cdot$ Prevalence

\section{Introduction}

Noise-induced hearing loss (NIHL) is a major occupational health hazard and is the second most reported occupational disease and injury in the USA (National Institute for Occupational Safety and Health [NIOSH] 1996a). It is an irreversible sensorineural hearing impairment caused by prolonged exposure to noise. NIHL causes communication interference that can substantially affect social integration, self-image, and the quality of life (National Institutes of Health [NIH] 1990). NIHL ranks among the most significant occupational health problems in many countries (Chen and Tsai 2003; Hessel 2000; Hong et al. 1998a; Kahan and Ross 1994; McBride et al. 2003; NIOSH 1996a). More than 30 million (one out of ten) American workers are exposed to loud noise that could result in hearing loss (NIOSH 1996a).

NIHL is one of most prevalent occupational health problems among construction workers. In particular, operating engineers (OEs) who operate heavy construction equipment are more exposed to hazardous noise than workers in other construction trade. Despite the risks of high noise exposure (Legris and Poulin 1998) and high degree of perceived hearing loss reported by OEs (Lusk et al. 1999), there are no published data on prevalence of NIHL in OEs in the USA. The purpose of this paper is to present the prevalence and characteristics of NIHL in OEs. 


\section{Background}

Noise exposure in construction workers

Noise is one of the most important occupational health hazards in the construction industry because of heavy machinery and equipment, transport vehicles, and noiseproducing tools operating at 90-130 dBA (Legris and Poulin 1998; McClymount and Simpson 1989). An estimated 6-7.6 million (US Bureau of Census 1992; US Department of Labor 1993) American workers are employed in the construction industry. More than half a million American construction workers are exposed to potentially hazardous levels of noise (Hattis 1998; Suter 2002). As a group, construction workers have the highest rates of work-related injury and illness in the USA (US Bureau of the Census 1995). Among these injuries, NIHL is the most common occupational hazard faced by these workers (The Center to Protect Workers Rights 1998).

Construction workers are constantly exposed to variable amounts of noise from their own equipment and activities, as well as noise from the tools and activities of others working around them (Franks 1990; Hager 1998). Individual construction worker's noise exposure level depends on how much noise the equipment he/she operates is making, how close the worker is to the equipment, and how long he/she is exposed (Legris and Poulin 1998; Schneider and Susie 1993). Several studies have identified common noise sources and documented exposure levels on construction sites (Anon 1984; Hattis 1998; Kerr et al. 2002; Legris and Poulin 1998; McClymount and Simpson 1989; Schneider and Susie 1993; Sinclair and Haflidson 1995; Utley and Miller 1985). Sound level measurements of construction equipment and activities conducted by McClymount and Simpson (1989) revealed a wide range of noise levels, from $85 \mathrm{dBA}$ of a hand saw to $122 \mathrm{dBA}$ of hammers striking a nail head on a stud.

The Center to Protect Workers Rights reported some typical exposure levels associated with construction equipment as measured on a new construction site over a 15-month time period (Schneider and Susie 1993). According to this report, high noise exposure was common to all trades throughout the construction site. In general, the noise levels bordered on or exceeded the OSHA permissible exposure level of $90 \mathrm{dBA}$ of an 8-h time-weighted average (TWA), such as pneumatic chipping hammer (103-113d BA), jack hammer (102-111 dBA), stud welder (101 dBA), concrete joint cutter (99-102 dBA), bulldozer (93-96 dBA), and earth tamper (90-96 dBA). Individual pieces of equipment varied considerably in sound levels by distance or function. For example, a Grade-all (an earthmoving truck) produced $94 \mathrm{dBA}$ at a distance of $10 \mathrm{ft}$ and $82 \mathrm{dBA}$ at $75 \mathrm{ft}$; a crane produced $75-80 \mathrm{~dB}$ when idling and 90-96 dB while operating (Schneider and Susie 1993).
More recent data reported by Legris and Poulin (1998) particularly demonstrate that the target population for this study, OEs, is exposed to harmful noise. According to their report, all heavy equipment operators except backhoe operators are exposed to an average of over 85 dBA TWA during their shift. Bulldozer operators are exposed to 96-99 dBA (Legris and Poulin 1998). Vibrating road roller operators and wheel roaders are exposed to 97 and $94 \mathrm{dBA}$, respectively. Asphalt road roller and asphalt spreader operators are exposed to 95 and $91 \mathrm{dBA}$, respectively. Grader operators are exposed to $89 \mathrm{dBA}$. Operations on loose ground consisting of soil sand generated $88 \mathrm{dBA}$ and crushed rock $90 \mathrm{dBA}$. Workers who operate backhoes and power shovels are exposed to 84 and $88 \mathrm{dBA}$, respectively. Although both have cabs that protect the workers from noise, on sunny days the large windows make the cab very hot unless it is air-conditioned. The operators are likely to open the cab door to expel hot air, thereby reducing the soundproofing. Although each worker generally has a favorite type of machine to operate, OEs tend to be masters of a variety of equipment. Workers who operate multiple pieces of equipment on a given shift are exposed to noise levels of $95 \mathrm{dBA}$ or greater. Others also measured noise levels for heavy equipment operators and reported 88$93 \mathrm{dBA}$ for crane operators (Kerr et al. 2002) and 105 dBA for bulldozer operators (Sinclair and Haflidson 1995).

Using a different approach to measure noise exposure, Lusk et al. (1999) asked construction workers $(n=$ 837) about their perception of exposure to high noise, defined as a noise level causing them to shout to be heard by a co-worker three feet or less away from them. The majority of workers (plumber/pipefitters, $70 \%$; carpenters, 78\%; OEs, $85 \%$; and national plumber pipefitter trainers, $69 \%$ ) reported that they were exposed to high noise on their recent job sites. Both noise monitoring data on the various types of noise exposures encountered in construction and the self-reported worker's perception on noise exposure demonstrate that construction workers, particularly OEs, are working in the presence of hazardous noise. Hence, for the purpose of saving time and costs, the present study did not repeat noise measurement for construction equipment and construction sites. Instead, this study focused on determining prevalence and characteristics of hearing loss among OEs who work in the presence of hazardous noise.

\section{Prevalence of NIHL in construction work}

Most construction workers lose some or a significantly large amount of their hearing after years at the trade (Schneider et al. 1995). A 1975 study of hearing in sheet metal workers in the USA revealed a high prevalence of hearing loss among workers ages 40 and older (Kenney and Ayer 1975). Based on their hearing loss index (25 dB of average loss in both ears at 1,2, and $3 \mathrm{kHz}$ ), $75 \%$ of 
workers in their $40 \mathrm{~s}$ and $100 \%$ between the ages of 50 and 60 years had hearing loss. Using audiometric data from both the Health Examination Survey (1960-1962) and the National Health and Nutrition Examination Survey (1971-1975), Norman and Smith (1998) reported that construction trade workers uniformly exhibited the greatest risk of NIHL across all audiometric measures, with manufacturing and mining workers experiencing the next highest risk. Blue-collar construction workers were more than three times as likely to suffer hearing loss as white-collar workers in certain industries outside of construction. While many health professionals in the construction industry suspect there is a high degree of hearing loss among OEs, currently there are no published reports as to the extent of hearing loss in this population. This serious lack of information provided an indication of the need for this study with the purpose of determining the prevalence and nature of hearing loss in OEs.

More comprehensive studies on NIHL in construction workers have been undertaken in other countries such as Germany (Arndt et al. 1996), Sweden (Schneider et al. 1995), and Canada (Roberts 1985, 1989). All these studies found a significantly high rate of NIHL among construction workers. A German study of older construction workers reported a prevalence ratio of hearing loss of $1.5(95 \%$ confidence level $=1.29-1.82)$ for construction workers compared to white-collar workers (Arndt et al. 1996). A Swedish study with over 100,000 construction workers reported that $50 \%$ of sheet metal workers ages $35-39$ years and $90 \%$ of workers ages $55-$ 59 years had hearing loss exceeding $30 \mathrm{~dB}$ at $4 \mathrm{kHz}$ in the left ear (Schneider et al. 1995). A Canadian study of 5,000 construction workers by the Workers' Compensation Board in British Columbia showed that $49 \%$ had NIHL (Roberts 1985). Another Canadian study of construction workers in 1989 who received audiometric tests $(n=32,800)$ revealed $50 \%$ of these workers had significant hearing loss, with $22 \%$ classified as severe to profound (Roberts 1989). Based on this review, this study conservatively hypothesized that at least $40 \%$ of OEs would show hearing loss at higher frequencies of 4 and $6 \mathrm{kHz}$.

\section{Method}

\section{Study site and participants}

The present study was conducted at the Training Center for the Local 324 of the International Union of OEs in a Midwestern state in the USA. The representatives of the Training Center were very interested in cooperating with the research team to conduct the study because: (1) they were well aware of the fact that OEs were exposed to numerous sources of noise in the construction sites in addition to the noise generated by the equipment they operated; and (2) annual audiometric test and training on use of HPDs were not legally required for construction workers and, thus, the majority of OEs had not been given these essential services for preventing NIHL.

Study participants were OEs in a Midwestern state, who were coming to the Training Center of the International Union of OEs for a 3-year apprentice certification course or the 8-h Hazardous Material (HAZMAT) refresher course. OEs operate heavy equipment such as bulldozers, graders, backhoes, asphalt road rollers, asphalt spreaders, and wheel loaders. The noise level for most of this heavy equipment is above $85 \mathrm{dBA}$. All OEs who came to the Training Center were invited to participate in the study and participation was voluntary.

\section{Data collection procedure}

Data were collected using a paper-pencil pre-hearing test questionnaire and an audiological assessment, including otoscopic examination and self-administered audiometric screening testing (SAAST), from January 2002 to April 2003. Prior to the audiometric test, an otoscopic examination of the aural and ear drum was performed by trained registered nurses to determine the presence of visible abnormalities, such perforated ear drums, signs or symptoms of ear disease, and excessive ear wax in the ear canals, which may affect the audiometric test or indicate the need for medical attention. Computer-based SAAST was part of a multi-media interactive hearing protection intervention implemented to prevent NIHL among OEs.

The SAAST was conducted for both ears at frequencies $0.5,1,2,3,4,6$, and $8 \mathrm{kHz}$, using a microprocessor pure-tone audiometer. The audiometer was calibrated according to the American National Standards Institute (ANSI) S3.6-1969 standard (ANSI 1969). The SAAST was conducted in the double-walled audiometric booth that conformed to the ANSI criteria for ambient noise in audiometric rooms (ANSI 1977).

A hearing threshold level (HTL) was defined as the lowest single intensity that the participant detected at least $50 \%$ of the time, with a minimum of three trials. HTLs were recorded in 5-dB increments. HTLs were obtained between 0 and $95 \mathrm{~dB}$ and a HTL of $95 \mathrm{~dB}$ was recorded if the participant did not respond to the limits of the test protocol. To minimize contamination of hearing loss by temporary threshold shift, workers were instructed to have a period of at least 14 quiet hours without noise exposure or to wear the HPDs at least on the day of the audiometric test.

\section{Data analysis}

For estimates of the prevalence of hearing loss, the following were applied. First, prevalence of hearing loss was estimated without any age adjustment to measure the real hearing status of construction workers, as rec- 
Table 1 Demographic characteristics of study participants $(N=623)$

\begin{tabular}{|c|c|}
\hline Variable & Mean (SD) \\
\hline Age (years) & $42.96(9.98)$ \\
\hline $\begin{array}{l}\text { Years in } \\
\text { construction }\end{array}$ & $18.14(10.93)$ \\
\hline $\begin{array}{l}\text { Hours of noise } \\
\text { exposure/day }\end{array}$ & $6.54(3.21)$ \\
\hline $\begin{array}{l}\text { Use of HPDs } \\
\text { ( } \% \text { of the time) }\end{array}$ & $48.27(32.02)$ \\
\hline Variable & Frequency $(\%)$ \\
\hline $\begin{array}{l}\text { Education level } \\
\text { (High school or above) }\end{array}$ & $581(93.4)$ \\
\hline \multicolumn{2}{|l|}{ Ethnicity } \\
\hline Caucasian/White & $556(89.8)$ \\
\hline African American/Black & $32(5.2)$ \\
\hline Native American/American & $13(2.1)$ \\
\hline \multicolumn{2}{|l|}{ Indian } \\
\hline Others & $11(1.9)$ \\
\hline Gender (male) & $566(91.6)$ \\
\hline Recreational hunting (yes) & $399(63.8)$ \\
\hline \multicolumn{2}{|l|}{ Perception of hearing } \\
\hline Excellent & $28(4.5)$ \\
\hline Very good & $110(17.8)$ \\
\hline Good & $266(43.0)$ \\
\hline Fair & $164(26.5)$ \\
\hline Poor & $51(8.2)$ \\
\hline $\begin{array}{l}\text { Problem understanding } \\
\text { what people say (yes) }\end{array}$ & $384(62.3)$ \\
\hline $\begin{array}{l}\text { Ringing and buzzing } \\
\text { in ears (yes) }\end{array}$ & $224(37.8)$ \\
\hline \multicolumn{2}{|l|}{ Types of equipment used } \\
\hline Loader & $436(70.0)$ \\
\hline Backhoe & $402(64.5)$ \\
\hline Bulldozer & $396(63.7)$ \\
\hline Excavator & $369(59.2)$ \\
\hline Forklift & $322(51.8)$ \\
\hline Roller & $278(44.6)$ \\
\hline End dump & $265(42.5)$ \\
\hline Bobcat & $257(41.3)$ \\
\hline Crane & $206(33.1)$ \\
\hline Tractor & $203(32.6)$ \\
\hline Scraper & $190(30.5)$ \\
\hline Boom truck & $166(26.6)$ \\
\hline
\end{tabular}

ommended by the NIOSH Criteria Document (NIOSH 1996b). Second, HTL of $25 \mathrm{~dB}$ was used as the low fence. Third, HTL measurements in the worst ear were used to measure the true extent of hearing loss if there is unequal hearing loss in the two ears. Fourth, rate of asymmetric hearing loss was calculated using the American Academy of Otolaryngology-Head and Neck Surgery (AAO-HNS)'s definition. According to the AAO-HNS (1997), asymmetric hearing loss is defined as HTL difference of greater than $15 \mathrm{~dB}$ at $0.5,1$, or $2 \mathrm{kHz}$ or $30 \mathrm{~dB}$ at 3,4 , or $6 \mathrm{kHz}$ between two ears. Fifth, prevalence of hearing loss was determined at each of the test frequencies $(0.5-8 \mathrm{kHz})$ and pure-tone threshold average (PTA) at $0.5,1,2$, and $3 \mathrm{kHz}(\mathrm{PTA}[0.5,1,2$, and 3]) and 4 and $6 \mathrm{kHz}(\mathrm{PTA}[4,6])$. The prevalence of hearing loss at $\operatorname{PTA}(0.5,1,2$, and 3$)$ was determined using the American Academy of Otolaryngology
(AAO)-79 Method, the most popular method for calculating material impairment of hearing to assess the risk of NIHL (AAO, 1979). The study was interested in prevalence of hearing loss at $\operatorname{PTA}(0.5,1,2$, and 3$)$ because understanding speech is the most critical function of human hearing. The study was particularly interested in workers' hearing status at $\operatorname{PTA}(4,6)$ because NIHL affects these higher frequencies earlier and more severely than the lower frequencies.

Lastly, the extent of hearing loss was then assessed using the grading system proposed by the World Health Organization (WHO, 1986): less than $25 \mathrm{~dB}$ (normal), 25-40 dB (slight), 41-60 dB (moderate), 61-80 dB (severe), and above $80 \mathrm{~dB}$ (extreme).

\section{Results}

Characteristics of the participants

A total of 772 workers completed SAAST, but 149 who reported noise exposure within $14 \mathrm{~h}$ before the hearing test were excluded from the analysis. Although we invited all OEs registered for HAZMAT training, participation was voluntary and about $5 \%$ of them did not participate in the study. It would be important to compare basic demographics between participants and nonparticipants to see any significant differences but it was not feasible because the registration list for HAZMAT training did not include individual OEs' demographic information other than their names and union identification numbers.

Demographic characteristics and selected variables of the study participants are summarized in Table 1 . The participants were predominantly middle-aged (mean = 43years), and had worked in construction for an extended period of time (mean $=18.1$ years, standard deviation $=10.9$ ). The study also asked workers about how many hours they were exposed to high noise, defined as a noise level causing them to shout to be heard by a co-worker three feet or less away from them. Workers reported a mean noise exposure of about $7 \mathrm{~h}$ per day on their jobsite. Although they should use HPDs all the time when in high noise, they reported using HPDs less than $50 \%$ of the time that was required. Participants were at least high school educated $(93 \%)$, Caucasian $(90 \%)$, and male $(92 \%)$. The majority of them $(64 \%)$ reported hunting as a recreational activity.

More than $65 \%$ of participants perceived their hearing was good. Regarding hearing-related symptoms, about $38 \%$ indicated they had ringing or buzzing in their ears, and over $60 \%$ reported a problem understanding what people say in noisy environments. As shown in Table 1, workers operated a variety of heavy equipment. Common types of construction equipment OEs operated included loader $(70.0 \%)$, backhoe $(64.5 \%)$, bulldozer $(63.7 \%)$, excavator $(59.2 \%)$, and forklift $(51.8 \%)$. A majority of the participants $(77 \%)$ reported that they operated more than two types of equipment. 
Table 2 Mean, standard deviation (SD) of HTLs, and prevalence of hearing loss at all test frequencies $(N=623)$

\begin{tabular}{|c|c|c|c|c|c|c|c|c|}
\hline \multicolumn{2}{|l|}{ HTLs (dB) } & \multicolumn{7}{|c|}{ Test frequency $(\mathrm{Hz})$} \\
\hline Mean (SD) & Right ear & $10.98(7.89)$ & $12.67(8.74)$ & $11.41(13.17)$ & $20.66(19.32)$ & $26.76(21.40)$ & $26.81_{* * *}(20.13)$ & $28.20(21.80)$ \\
\hline \multicolumn{2}{|c|}{$\begin{array}{l}\text { Mean difference between } \\
\text { two ears }\end{array}$} & $0.33^{\mathrm{NS}}$ & $-0.66^{*}$ & $1.09^{*}$ & $3.05^{* *}$ & $3.26^{* *}$ & $3.13^{* *}$ & $1.81^{*}$ \\
\hline Mean (SD) & Worst ear & $13.12(9.09)$ & $14.50(10.09)$ & $15.07(15.74)$ & 27.04 (20.99) & $33.80(22.55)$ & $34.11(21.23)$ & $34.94(23.31)$ \\
\hline
\end{tabular}

Note: NS non-significant; ${ }^{*} p<0.05,{ }^{* *} p<0.001$.

${ }^{a}$ Hearing loss was calculated based on HTLs in the worst ear between left and right ears.

Approximately $60 \%$ of workers indicated that they operated several $(>5)$ different machines.

Prevalence of hearing loss

\section{Hearing loss at single frequencies}

The means and standard deviations of HTLs for both ears and the worst ear at all test frequencies are presented in Table 2, along with mean difference between the left and right ears. There was a statistically significant difference in the mean HTLs between the left and the right ears at all test frequencies but $0.5 \mathrm{kHz}$. The left ear showed significantly poorer hearing at frequencies of $2-8 \mathrm{kHz}$ and had slightly better hearing at $1 \mathrm{kHz}$ than the right ear $(p<0.05)$. As shown in Table 2, the differences of the mean HTLs between the two ears are clearly bigger in higher frequencies $(3-8 \mathrm{kHz})$, most notably at 3,4 , and $6 \mathrm{kHz}$, than in lower frequencies
$(0.5-2 \mathrm{kHz})$. Mean differences between the left and the right ears for frequencies lower than $2 \mathrm{kHz}$ were smaller than $1.1 \mathrm{~dB}$ and up to about $3.3 \mathrm{~dB}$, the largest HTLs differences at $4 \mathrm{kHz}$. In both ears, $6 \mathrm{kHz}$ had the greatest mean HTL, compared with the other tested frequencies. However, differences among mean HTLs at 4,6 , and $8 \mathrm{kHz}$ are negligibly small. Based on the AAOHNS (1997) definition of asymmetric hearing, the study found that about $19 \%$ of the workers $(113 / 623)$ had asymmetric hearing.

Mean HTLs for both ears were within the range of normal hearing for test frequencies of $0.5-3 \mathrm{kHz}$, whereas average HTLs at higher frequencies of $4-8 \mathrm{kHz}$ were between 27 and $30 \mathrm{~dB}$. For the worst ear, mean HTLs at higher frequencies (above $3 \mathrm{kHz}$ ) showed above $25 \mathrm{~dB}$.

Prevalence of hearing loss at single frequencies estimated based on the HTLs at the worst ear is also presented in Table 2. Prevalence of hearing loss dramatically increases at the higher frequencies (from
Fig. 1 Mean and standard deviation $(S D)$ of HTLs at all test frequencies $(n=623)$

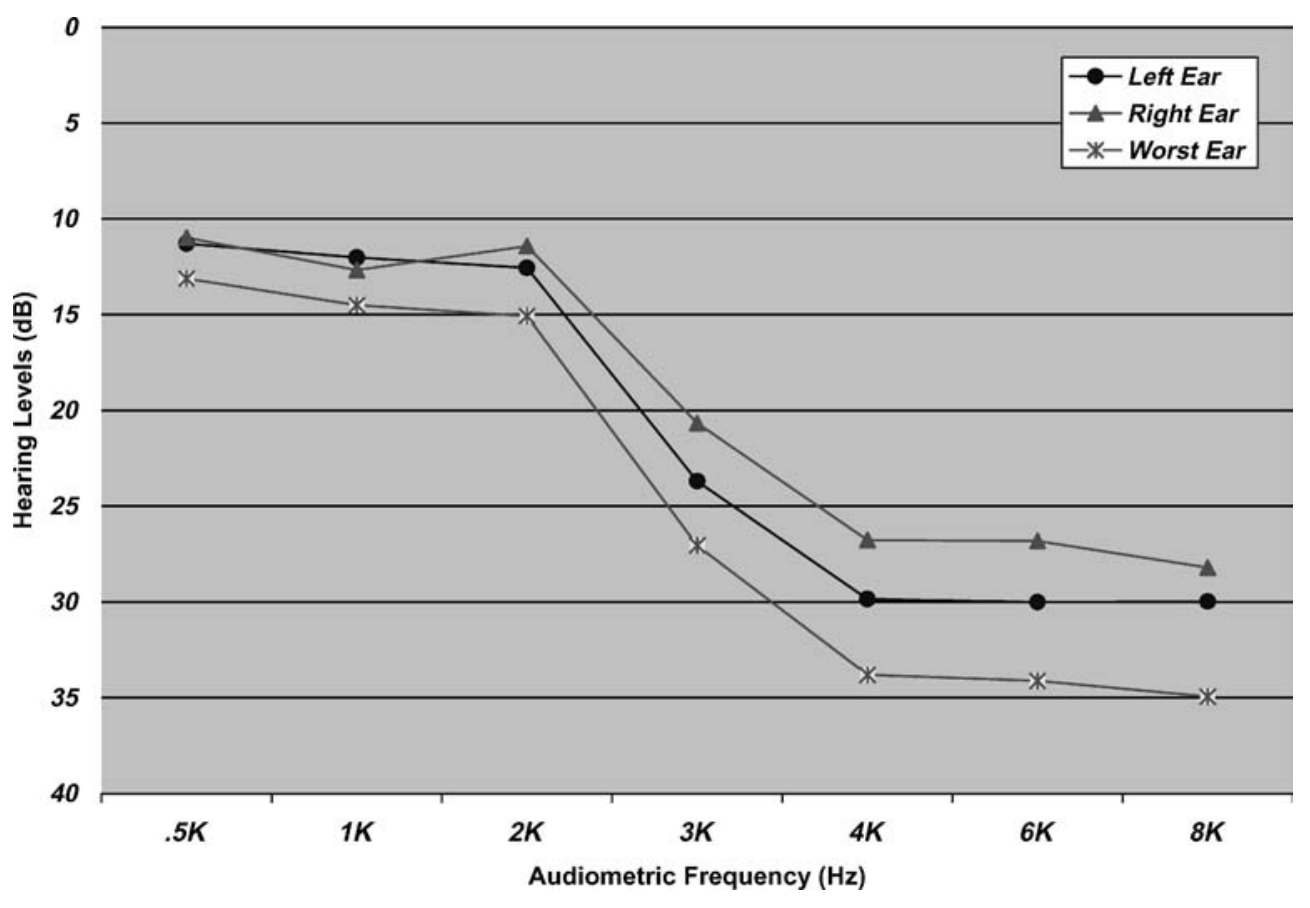


Table 3 Distribution of hearing loss at PTA $(0.5,1,2$, and 3$)$ and $\operatorname{PTA}(4,6)$

\begin{tabular}{lllll}
\hline $\begin{array}{l}\text { Extent of } \\
\text { hearing loss }\end{array}$ & \multicolumn{2}{l}{$\operatorname{PTA}(0.5,1,2$, and 3) } & & \multicolumn{2}{c}{$\operatorname{PTA}(4,6)$} & \\
\cline { 2 - 3 } & $n$ & $\%$ & & $n$ \\
\hline Normal $(<25 \mathrm{~dB})$ & 481 & 79.5 & 244 & 39.2 \\
Mild $(25-40 \mathrm{~dB})$ & 95 & 15.7 & 129 & 20.7 \\
Moderate $(41-60 \mathrm{~dB})$ & 22 & 3.6 & 134 & 21.5 \\
Severe $(61-80 \mathrm{~dB})$ & 7 & 1.2 & 80 & 12.8 \\
Extreme $(>80 \mathrm{~dB})$ & - & - & 16 & 2.6 \\
\hline
\end{tabular}

$3 \mathrm{kHz}$ ). As presented in Table 2, more than $45 \%$ of OEs showed hearing loss at $3 \mathrm{kHz}$. A vast majority $(60 \%$ and above) of them showed hearing loss at 4-8 kHz.

Mean HTLs for the both ears and the worst ear are also depicted in Fig. 1. As seen in Fig. 1, mean HTLs steadily increase as frequency increases in both ears and the worst ear, dramatically increased at $3 \mathrm{kHz}$ and flattened at 4, 6, and $8 \mathrm{kHz}$. The mean HTLs in the higher frequency range from 4 to $8 \mathrm{kHz}$ increased up to 27-35 dB.

Hearing loss at $\operatorname{PTA}(0.5,1,2$, and 3) and $\operatorname{PTA}(4,6)$

The means of HTLs at $\operatorname{PTA}(0.5,1,2$, and 3) and $\operatorname{PTA}(4,6)$ were $17.4 \mathrm{~dB}$ and $33.9 \mathrm{~dB}$, respectively. As expected, a greater prevalence of hearing loss was shown at $\operatorname{PTA}(4,6)$, most noise sensitive frequencies, than $\operatorname{PTA}(0.5,1,2$, and 3). About 60\% (359/623) of the workers had abnormal hearing at the $\operatorname{PTA}(4,6)$ whereas $38.5 \% \quad(233 / 623)$ workers showed hearing loss at $\operatorname{PTA}(0.5,1,2$, and 3).

Distribution of extent of hearing loss at two indicators is presented in Table 3. As expected, severity of hearing loss increased at $\operatorname{PTA}(4,6)$. About $37 \%$ showed moderate hearing loss $(\mathrm{HTL}>40 \mathrm{~dB})$ at $\operatorname{PTA}(4,6)$, which was significantly higher than that at lower frequency hearing loss at $\operatorname{PTA}(0.5,1,2$, and 3$)$. The study also revealed that almost all OEs (99.6\%) with lower frequency hearing loss at $\operatorname{PTA}(0.5,1,2$, and 3$)$ had higher frequency hearing loss at $\operatorname{PTA}(4,6)$, whereas only
Fig. 2 Mean hearing levels at single frequency by years in construction (worst ear) $(n=623)$

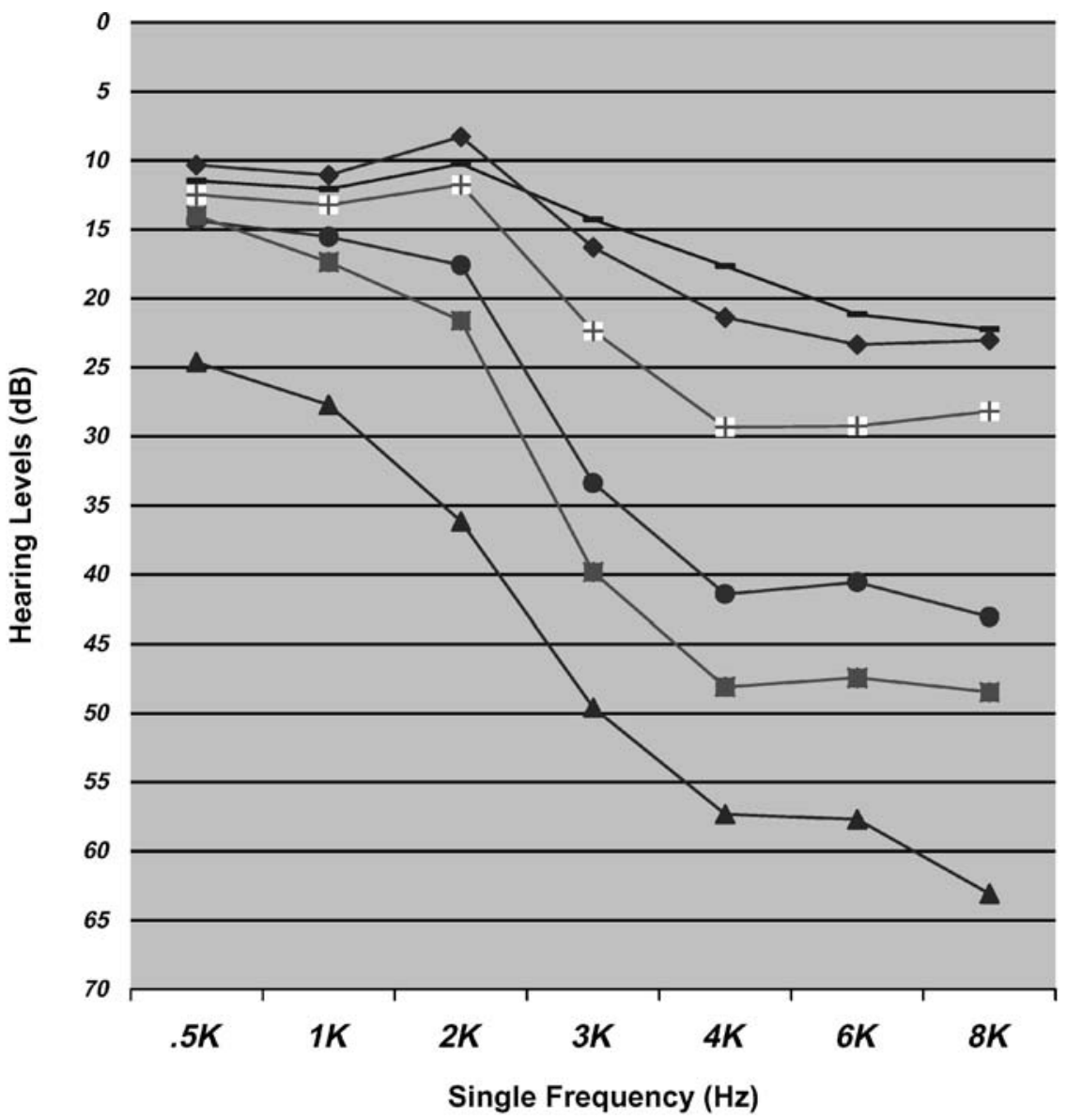

$-<5$ yrs $\longrightarrow-5-9$ yrs $\longrightarrow 10-19$ yrs 
Table 4 Prevalence of hearing loss at PTA(0.5, 1, 2, and 3) and PTA(4, 6) by years in construction

\begin{tabular}{|c|c|c|c|c|}
\hline \multirow[t]{2}{*}{ Years in construction } & \multirow[t]{2}{*}{$\begin{array}{l}\text { Mean age } \\
\text { (year) }\end{array}$} & \multirow[t]{2}{*}{$\begin{array}{l}\text { Number } \\
\text { of workers }\end{array}$} & \multicolumn{2}{|c|}{$\begin{array}{l}\text { Number of workers }(\%) \\
\text { with hearing loss at two indicators }\end{array}$} \\
\hline & & & $\operatorname{PTA}(0.5,1,2$, and 3$)$ & $\operatorname{PTA}(4,6)$ \\
\hline$<5$ & 34.51 & 92 & $7(7.6)$ & $28(30.4)$ \\
\hline $5-9.9$ & 34.31 & 61 & $6(9.8)$ & $16(26.2)$ \\
\hline $10-19.9$ & 39.03 & 169 & $21(12.4)$ & $86(51.2)$ \\
\hline $20-29.9$ & 46.29 & 140 & $38(27.1)$ & $105(75.0)$ \\
\hline $30-39.9$ & 53.85 & 116 & $43(37.1)$ & $103(89.6)$ \\
\hline$\geq 40$ & 60.80 & 13 & $6(46.2)$ & $13(100.0)$ \\
\hline Total & 42.94 & 591 & $121(20.5)$ & $351(59.6 s)$ \\
\hline
\end{tabular}

$34 \%$ of OEs with higher frequency hearing loss at $\operatorname{PTA}(4,6)$ demonstrated hearing loss at $\operatorname{PTA}(0.5,1,2$, and 3 ).

\section{Hearing loss by working years in construction industry}

In order to see the trends of hearing loss by years worked in construction, the HTLs at the single test frequency and three indicators were categorized into the following six construction year groups: less than $5(n=$ 92), 5-9 $(n=61), 10-19(n=169), 20-29(n=140), 30-$ $39(n=116)$, and 40 years and over $(n=13)$. The mean HTLs for these construction year groups are presented in Fig. 2. The breakdown by years worked in construction clearly demonstrates, as it may be expected, progressive hearing loss with years in construction.

As shown in Fig. 2, workers' hearing sensitivity begins to decline in the higher frequencies of 3-8k Hz even in the shorter construction year group ( $>5$ years). This decline continues as the construction year increases, as is demonstrated by higher HTLs among the workers with longer years in construction. A noise notch, a typical characteristic of NIHL, was not apparent for all construction year groupings. The pattern of hearing loss showed among workers who had worked in construction for longer than 20 years (mean age $>45$ years) is very characteristic of sloping configuration from both noise and aging. The extent of hearing loss at two indicators is presented by years worked in construction in Table 4, along with mean ages of workers. The prevalence of hearing loss among workers with longer work history in construction industry is much higher than that in workers with shorter years in construction. As shown in Table 4, a vast majority of workers who had worked in construction for a longer period (over 20 years) showed hearing loss at noise sensitive frequencies $(4-6 \mathrm{kHz})$ : $75 \%$ of workers with $20-29$ years; $89 \%$ of workers with 30-39 years; and $100 \%$ of workers with over 40 years in construction.

\section{Use of HPDs and hearing loss}

Use of HPDs was measured by two questions regarding the self-reported percentage of time (0-100\%) HPDs were used at the most recent jobsite and in the past
12 months at work. Because of strong correlations between these measures $(r=0.91, p<0.01)$, the averaged score of the two items was used to reflect workers' use of HPDs. On average, they used HPDs $48 \%$ of the time when they should have in high noise, which was far less than the $100 \%$ use needed to prevent NIHL (Dear 1998).

The study further investigated if workers' use of HPDs has an effect on their hearing loss at noise-sensitive higher frequencies $(4-6 \mathrm{kHz})$. Bivariate correlation of HPD use with HTLs at PTA $(4,6)$ showed significant inverse association $(r=-0.134, p<0.001)$. Workers who used HPDs more frequently had significantly better hearing than those who did less frequently. The relationship between HPD use and hearing ability was further examined by comparing prevalence of hearing loss at $\operatorname{PTA}(4,6)$ between the two (MORE, LESS) user groups. MORE user groups $(n=138)$ included workers who used HPDs almost all the time $(\geq 80 \%)$ and LESS user groups $(n=450)$ were those who used HPDs less than $80 \%$ of the time they were required. Two users group did not show significant differences in their demographic characteristics such as age (42.2 vs 42.8 years) and years of working in construction (17.4 vs 18.1 years). Significant difference in prevalence of higher frequency hearing loss was identified between the MORE and LESS user groups $(p<0.001)$. Prevalence of hearing loss among the MORE user group was significantly lower than the LESS user group (47 vs $64 \%$, $p<0.01)$.

\section{Discussion}

Findings of this study clearly demonstrated that OEs faced significant risk of hearing loss. The prevalence of hearing loss showed in OEs was far greater than anticipated. Based on the review of the earlier studies with construction workers, the present study conservatively hypothesized that about $40 \%$ of OEs would have hearing loss at higher frequencies (4 and $6 \mathrm{kHz}$ ). Surprisingly, the results of the present study uncovered that over $60 \%$ of OEs showed hearing loss at PTA $(4,6)$. It should be mentioned that actual prevalence could be slightly higher or lower than the reported $60 \%$ because the study did not have information on hearing status for 
those who were invited but did not participate in the study. This may be a shortcoming of the study.

OEs, perhaps more than most other workers in construction trades, require long hours in close proximity to the noisy heavy equipment. Progressive damage to their hearing was noticed at higher frequencies above $3 \mathrm{kHz}$, and this risk for hearing loss was especially heightened among OEs with longer years of working in construction industry, presumably because longer years in construction means more years of noise exposure. Prevalence rates for both lower and higher frequencies accelerated as their tenure in construction increased. For example, compared to OEs with a short tenure in construction ( $<5$ years), OEs who worked in construction industry for over 40 years demonstrated strikingly higher prevalence of hearing loss for both lower ( $8 \mathrm{vs} 46 \%$ ) and for higher frequencies (30 vs 100\%).

Assessing lower and higher frequencies separately takes into account the fact that NIHL preferentially affects the higher frequencies, with hearing loss beginning characteristically around 4 or $6 \mathrm{kHz}$ before the deterioration of hearing loss at lower frequencies as the higher frequency loss progresses. This study confirmed the prevalence of hearing loss at 4 and $6 \mathrm{kHz}$, attributable to noise exposure, was far exceeded than hearing loss at lower frequencies critical to the ability to understand speech. These findings are consistent with earlier reports (Dobies 1995; Hong et al. 1998a; May 2000; NIH 1990; Orgler et al. 1987). The study also showed that almost all $(99.6 \%)$ workers with hearing loss at $\operatorname{PTA}(0.5,1,2$, and 3$)$ showed hearing loss at $\operatorname{PTA}(4,6)$ as well, whereas only $34 \%$ of workers with hearing loss at $\operatorname{PTA}(4,6)$ had hearing loss at $\operatorname{PTA}(0.5,1$, 2 , and 3 ). Therefore, hearing loss at the higher frequency may be used as an indication of susceptibility to effects of noise and the likelihood of progression of loss to lower frequencies.

A large proportion $(62 \%)$ of OEs in this study reported difficulty in understanding people's conversation in noisy environment. Any level of NIHL may muffle high-frequency sounds such as whistles or buzzers and may result in difficulty discriminating speech consonant sounds such as those in the words fish and fist, particularly in noisy environments with background noise, many voices, or room reverberation (Smoorenburg 1992).

The left ear had acquired significantly more loss than the right ear in the study population, which corroborates previously reported study findings (Broste et al. 1989; Marvel et al. 1991; Pirila et al. 1992; Simpson et al. 1993). NIHL, for reasons that are still not yet clearly identified, usually become manifest first and rapid in the left ear (Gasaway 1994; Rudin et al. 1988; Touma 1992). Although no definitive causes were examined for poorer hearing in the left ear among the study participants, some plausible explanations were considered. First, poorer hearing in the left may reflect OEs' unique directional noise exposure from operating heavy construction equipment. Most OEs may look over their right shoulder when they operate heavy equipment, and thus their left ear was more exposed to the noise generated by the machine's engine. Also, some workers may have the window open during their work when they operated equipment with no air conditioning during summer season. This phenomenon was also reported by the study with farmers who presumably operate tractors (Broste et al. 1989; Marvel et al. 1991). Another possible explanation for the poorer hearing in the left ear is that a large proportion of OEs $(64 \%)$ had shot firearms for hunting. Since most individuals are right-handed, the muzzle blast from a rifle or shotgun reaches the left ear at a higher level than the somewhat protected right ear. Using firearms, chain saws, and other portable power tools also tends to expose the left ear more directly to the source of noise (Marvel et al. 1991).

Occupational health professionals agree on the importance of workers' use of HPDs in preventing NIHL. The present study showed protective effect of using HPDs; workers who reported frequent use of HPDs had significantly better hearing. Although the study could not determine a definitive causal relationship between the use of HPDs and hearing loss because of its cross-section nature, this finding corroborates previous studies. For example, Savell and Toothman (1987) found no loss in hearing ability in 265 employees who consistently used HPDs, even though they worked in areas with high noise exposures (86$103 \mathrm{dBA})$. In the study with Korean airport workers exposed to high noise ( $\geq 85 \mathrm{dBA}, 8$-h TWA), Hong et al. (1998b) found that workers who used HPDs consistently had significantly less hearing loss than those who did not. A more recent study in Canada reported that construction workers who always wore HPDs showed better hearing, compared to those who did not (Hessel 2000).

This study is considered as one of the first ones assessed prevalence and characteristic pattern of NIHL and demonstrated a protective effect of HPD use on hearing among OEs in the USA, which are considered valuable information. However, the progression of this loss and its relationship with use of HPDs should be studied systematically using serial audiograms in a carefully designed longitudinal study.

NIHL has an insidious onset and may be well advanced by the time that it gives rise to appreciable disability. The first sign of NIHL is a V-shape dip or notch in the audiogram with the maximal HTL at 4 or $6 \mathrm{kHz}$. Interestingly, a $\mathrm{V}$-shaped notch at 4 or $6 \mathrm{kHz}$, a typical audiometric characteristic of NIHL, was not present in this population. This is a common pattern of audiogram for workers who have been exposed to loud noise for many years without proper protection (Suter 2002). Lower frequencies $(0.5-2 \mathrm{kHz})$ take longer to get affected by noise than the higher frequencies $(3-6 \mathrm{kHz})$. Workers can barely notice early stages of NIHL because they do not notice any interference in their daily conversation. The noise notch flattens with increasing noise exposure, and may eventually become indistinguishable 
from the changes of aging (presbycusis), where the hearing shows a gradual deterioration at the higher frequencies. Early detection of such loss through periodic audiometric tests may assist in prevention of further loss, and recognition of existing loss is important for educational and medicolegal purposes. The OSHA recognized that an annual audiometric test is essential for an effective hearing conservation program (USDL OSHA 1983). Unfortunately, an audiometric test, a key element of a hearing conservation program, was not being provided to the majority of construction workers in the USA. According to the 1997 Michigan annual report on NIHL, for example, less than $4 \%$ of newlyreported NIHL cases in construction workers had regular audiometric test performed at their jobs (Reilly et al. 1998).

NIHL is permanent and cannot be cured because hair cells, once damaged, do not regenerate. NIHL has resulted in significant monetary costs and human suffering. Loss of hearing negatively affects an individual's quality of life, social interaction, and personal safety in the workplace. Fortunately, it is one of the most preventable occupational health problems (NIH 1990; NIOSH 1988). Hence, more comprehensive hearing conservation program including a periodic audiometric testing and training on use of HPDs should be implemented in the construction industry. The OSHA rules (29 CFR 1910.95) in the USA require periodic noise exposure monitoring, engineering and administrative controls, personal hearing protection, annual audiometric test, and worker training. Currently, this requirement does not apply to construction workers. The construction industry has been covered by its own noise standard, 29 CFR 1926.52 (USDL OSHA 1971), which simply requires that all workers exposed to noise at or above an 8-h TWA of $90 \mathrm{dBA}$ must be provided with protection against hazardous noise. It should be noted that all permissible noise exposure limits mentioned in this paper are only relevant to the USA. As different countries have their own national noise standards and recommendations, interpretation of reported findings should be done accordingly.

Hearing conservation programs in construction have been in place in other countries such as Sweden and Canada since 1969 and mid-80s, respectively (Schneider et al. 1995). The evaluation results of Swedish program for each decade demonstrated that the prevalence of hearing loss had declined across age groups (Schneider et al. 1995). Ideally, replacing and modifying construction equipment to decrease noise level should be the priority. But it is reasonable to recognize that eliminating the source of noise by replacing old machines with new quiet ones is costly and not always possible. Furthermore, the nature of the construction work such that the workers are exposed to noise generated by their own tools or equipment as well as other noise generally prevalent in the constructions sites makes it difficult to control noise exposure.
Considering that construction workers are constantly changing the workplace, having several employers at multiple jobsites and prevalently self-employed, it might not be practical for contractors to provide regular audiometric test for workers who may only work for them a few days or a few weeks. An innovative approach with cooperation among contractors, trade unions, and government bodies is necessary to provide construction workers with annual audiometric test and hearing protection training. This study demonstrated a successful collaboration between $\mathrm{OE}$ trade union and a research university in implementing self-administered audiometric screening as a part of hearing protection intervention. It is hoped this work will serve as a prototype for effective collaboration among researchers, labor unions, contractors, and workers to promote workers' health and safety.

Acknowledgments This study was supported by research grant (5R01 OH04034-01A1) from Centers of Disease Control and Prevention-National Institute for Occupational Safety and Health (CDC-NIOSH, Principal Investigator-Dr. OiSaeng Hong). Its contents are solely the responsibility of the author and do not necessarily represent the official views of the CDC-NIOSH. The author is thankful for union leaders at the Local 324 Training Center of the International Union of Operating Engineers for their collaboration and all operating engineers who participated in this study. Also, the author would like to acknowledge Mr. Alonzo LaGrone and Mr. Jim Roll for their assistance in preparation of this manuscript and data analysis, respectively.

\section{References}

American Academy of Otolaryngology-Head and Neck Surgery (AAO-HNS) (1997) Otologic Referral Criteria for Occupational Hearing Conservation Programs. Alexandria, VA

American Academy of Otolaryngology (AAO) (1979) Committee on hearing and equilibrium and the American Council of Otolaryngology Committee on the medical aspects of noise: guide for the evaluation of hearing handicap. J Am Med Assoc 241(19):2055-2059

American National Standards Institute (ANSI) (1969) Specification for audiometers. American National Standards Institute, New York (ANSI-S3.6-1969)

American National Standards Institute (ANSI) (1977) Criteria for Permissible Ambient Noise during Audiometric Testing. American National Standards Institute, New York (ANSIS3.1-1977)

Anon T (1984) Exposure of construction workers to noise. Technical Note 115. Construction Industry Research and Information Association, London

Arndt V, Rothenbacher D, Brenner H et al (1996) Older workers in the construction industry: results of a routine health examination and a five-year follow up. Occup Environ Med 53:686-691

Broste SK, Hansen DA, Strand RI et al (1989) Hearing loss among high school farm students. Am J Public Health 79:619-622

Chen J-D, Tsai J-Y (2003) Hearing loss among workers at an oil refinery in Taiwan. Arch Environ Health 58(1):55-58

Dear TA (1998) Updating damage risk criteria to include performance under workplace noise regulations. J Occup Hear Loss 1(1):61-66

Dobies RA (1995) Prevention of noise induced hearing loss. Arch Otolaryngol Head Neck Surg 121:385-391

Franks JR (1990) Noise in the construction industry and its effect on hearing. Hear Instruments 41:18-21 
Gasaway DC (1994) Noise-induced hearing loss. In: McCunney RJ, Brandt-Rauf PW (eds) A practical approach to occupational and environmental medicine, 2nd edn. Little, Brown and Company, New York, pp 230-247

Hager LD (1998) Sound exposure profiling: A noise monitoring alternative. Am Ind Hyg Assoc J 59:414-418

Hattis D (1998) Occupational noise sources and exposures in construction industries. Hum Ecol Risk Assess 4:1417-1441

Hessel PA (2000) Hearing loss among construction workers in Edmonton, Alberta, Canada. J Occup Environ Med 42(1):5763

Hong O, Chen SC, Conrad KM (1998a) Noise-induced hearing loss among male airport workers in Korea. Assoc Am Occup Health Nurses J 46(2):67-75

Hong O, Wilber LA, Furner S (1998b) Use of hearing protection and hearing threshold levels among noise-exposed Korean airport workers. J Occup Hear Loss 1(4):271-279

Kahan E, Ross E (1994) Knowledge and attitude of a group of South African mine workers towards noise induced hearing loss and the use of hearing protective devices. S Afr J Commun Disord 4:37-47

Kenney GD, Ayer HE (1975) Noise exposure and hearing levels of workers in the sheet metal construction trade. Am Ind Hyg Assoc J 28:626-632

Kerr MJ, Brosseau L, Johnson CS (2002) Noise levels of selected construction tasks. Am Ind Hyg Assoc J 63(3):334-339

Legris M, Poulin P (1998) Noise exposure profile among heavy equipment operators, associated laborers, and crane operators. Am Ind Hyg Assoc J 59:774-778

Lusk SL, Hong O, Ronis DL et al (1999) Test of the effectiveness of an intervention to increase use of hearing protection devices in construction workers. Hum Factor 41(3):487-494

Marvel ME, Pratt DS, Marvel LH et al (1991) Occupational hearing loss in New York dairy farmers. Am J Ind Med 20:517531

May JJ (2000) Occupational hearing loss. Am J Ind Med 37:112120

McBride DI, Firth HM, Herbison GP (2003) Noise exposure and hearing loss in agriculture: A survey of farmers and farm workers in the Southland region of New Zealand. J Occup Environ Med 45(12):1281-1288

McClymount IG, Simpson DC (1989) Noise levels and exposure patterns of power tools. J Laryngol Otol 103:1140-1141

National Institute for Occupational Safety and Health (NIOSH) (1988) A Proposed National Strategy for the Prevention of Noise-Induced Hearing Loss. Department of Health and Human Services, Cincinnati, OH (Publication Number NIOSH 89-103)

National Institute for Occupational Safety and Health (NIOSH) (1996a) National Occupational Research Agenda. US Department of Health and Human Services, Public Health Service, Center for Disease Control and Prevention, Washington, DC

National Institute for Occupational Safety and Health (NIOSH) (1996b) Criteria for a Recommended Standard, Noise Exposure-Revised Criteria. US Department of Health and Human Services, Public Health Service, Center for Disease Control and Prevention, Washington, DC

National Institutes of Health (NIH) (1990) Consensus development conference statement. US Department of Health and Human Services, Bethesda, MD, Noise Hear Loss 8(1)

Norman JW, Smith KR (1998) Risk of hearing loss among male construction workers: Implications for worksite regulation. In: Sorkin A, Farquhar I, Sorkin A (eds) Research in human capital and development: economic and social aspects of occupational and environmental health. JAI Press, London, pp 73-98
Orgler GK, Brownson PJ, Brubaker WW et al (1987) American occupational medicine association noise and hearing conservation committee guidelines for the conduct of an occupational hearing conservation program. J Occup Med 29:981-982

Pirila T, Jounio EK, Sorri M (1992) Left-right asymmetries in hearing threshold levels in three age groups of a random population. Audiology 31:150-161

Reilly MJ, Rosenman KD, Kalinowski DJ (1998) Occupational noise-induced hearing loss surveillance in Michigan. J Environ Occup Med 48(8):667-674

Roberts ME (1985) Potential for Noise-Induced Hearing Loss Claims in the Building Construction Industry. British Columbia Workers Compensation Board, Vancouver, Canada

Roberts ME (1989) Hearing Test Results in the Construction Industry. British Columbia Workers Compensation Board, Vancouver, Canada

Rudin R, Rosenhall U, Svardsudd K (1988) Hearing capacity in samples of men from the general population: The study of men born in 1913 and 1923. Scand Audiol 17:3-10

Savell JF, Toothman EH (1987) Group mean hearing threshold changes in a noise-exposed industrial population using personal hearing protectors. J Acoust Soc Am 48:23-27

Schneider S, Susie P (1993) Final report: an investigation of health hazards on a new construction project. The Center to Protect Workers' Rights, Washington, DC (Report OSH 1-93)

Schneider S, Johanning E, Belard J et al (1995) Noise, vibration, and heat and cold. Occup Med State Art Rev 10(2):363-383

Simpson TH, McDonald D, Stewart M (1993) Factors affecting laterality of standard threshold shift in occupational hearing conservation programs. Ear Hear 14:322-432

Sinclair J, Haflidson W (1995) Construction noise in Ontario. Appl Occup Environ Hyg 10(5):457-460

Smoorenburg GF (1992) Noise-induced hearing loss. In: McCunney RJ, Brandt-Rauf PW (eds) A practical approach to occupational and environmental medicine, 2nd edn. Little, Brown and Company, New York, pp 230-247

Suter AH (2002) Hearing conservation manual, 4th edn. Council for Accreditation in Occupational Hearing Conservation, Milwaukee, WI

The Center to Protect Workers Rights (1998) The Construction Chart Book: Noise-induced Hearing Loss in Construction. Washington, DC: United States Government Printing Office

Touma JB (1992) Controversies in noise-induced hearing loss. Ann Occup Hyg 36(2):199-209

US Department of Labor (USDL), Occupational Safety and Health Administration (OSHA). (1971). Occupational noise standard for construction workers (29 CFR 1926.52). US Department of Labor, Washington, DC

US Bureau of the Census (1992) Statistical abstract of the United States, 112th edn. US Bureau of the Census, Washington DC

US Bureau of the Census (1995) Statistical Abstract of the United States, 115th edn. United States Government Printing office, Washington, DC

US Department of Labor (USDL), Bureau of Labor Statistics (1993) Employment and Earnings. US Department of Labor, Washington, DC

US Department of Labor (USDL), Occupational Safety and Health Administration (OSHA) (1983) Occupational noise exposure, hearing conservation amendment; Final Rule. Fed Regist 48:9738-9785

Utley WA, Miller LA (1985) Occupational noise exposure on construction sites. Appl Acoustics 18:293-303

World Health Organization (WHO) (1986) Prevention of Deafness and Hearing Impairment. Thirty-ninth world health assembly, 1986 EB 79/10, Annex A 39/14. World Health Organization, Geneva, Switzerland, pp 1-18 